\title{
APLIKASI KELAS ONLINE JURUSAN TEKNIK INFORMATIKA FAKULTAS TEKNIK UNIVERSITAS PALANGKA RAYA
}

\author{
Nova Noor Kamala Sari ${ }^{a, 1^{*}}$, Deddy Ronaldo ${ }^{\mathrm{b}, 2}$ \\ a Jurusan Teknik Informatika FT UPR, Jl H. Timang Tunjung Nyaho \\ ${ }^{\mathrm{b}}$ Jurusan Teknik Informatika FT UPR, J1 H. Timang Tunjung Nyaho \\ nova.nks@gmail.com ${ }^{1}$; deddy.ronaldo@gmail.com ${ }^{2}$ \\ * corresponding author
}

ARTICLE INFO

\section{Keywords}

Application of online class UML-based Web Engineering $(U W E)$

\begin{abstract}
The designed online class is used to provide additional values to the learning process in the Department of Informatics Engineering of University of Palangka Raya. It basically does not replace the entire learning process because the learning process is thus far implemented in the classroom. Yet, the application of online classroom provides extra features, such as creating written materials directly on the web and uploading the materials in PDF or PPT which then can be obtained directly by students on the web. Students can upload their given assignments on the web as well; therefore the lecturers no longer need to bring a stack of printed reports or papers of the student assignments. Modeling application of online class in this research aims at applying UML-based Web Engineering method (UWE) apart from waterfall engineering method which is often taught to the students of Department of Informatics Engineering of University of Palangka Raya.

The result of this research shows that the website program on online class can be implemented by the lecturers and students majoring in Informatics Engineering by applying model application of UML-based Web Engineering method (UWE).
\end{abstract}

\section{PENDAHULUAN}

\subsection{Latar Belakang}

Peningkatan kapasitas pendidikan mengharuskan kita berbenah baik dalam hal sistem pendidikan, metode pendidikan maupun media pembelajaran yang digunakan. Seiring dengan berkembangnya teknologi Informasi saat ini maka kita sebagai pengajar harus bisa memanfaatkan kemajuan teknologi yang ada dengan sebaik- baiknya guna memaksimalkan potensi peserta didik dan kemudahan dalam menyampaikan bahan ajar.

Aplikasi Kelas Online merupakan proses pembelajaran yang memanfaatkan teknologi informasi, dalam hal ini memanfaatkan media online seperti internet sebagai metode penyampaian, interaksi dan fasilitasi. Di dalamnya terdapat dukungan layanan belajar yang dapat dimanfaatkan oleh peserta belajar yang dapat membantu peserta belajar apabila mengalami kesulitan. Selain itu juga tersedia rancangan sistem pembelajaran yang dapat dipelajari dan diketahui oleh tiap peserta belajar. Salah satu keunggulan dari kelas online ini adalah pada saat penyampaian materi perkuliahan bisa diunduh dimanapun serta pada saat pengumpulan tugas yang diberikan kepada peserta didik dapat dilakukan dengan cara upload softcopy hasil tugas ke aplikasi online/ website yang telah tersedia sehingga pengajar tidak perlu memeriksa email satu persatu, selain itu dengan memanfaatkan sistem aplikasi online ini juga mengurangi atau bahkan meniadakan pengumpulan tugas secara hard copy karena dinilai kurang efisien. 


\section{JURNAL TEKNOLOGI INFORMASI}

[E-ISSN 2656-0321]

[Vol 12. No. 1]

Jurnal Keilmutan dan Aplikasi Bidang Teknik Iniormatilka

[Januari 2018]

Pemanfaatan aplikasi online untuk pengajaran dinilai sangat bermanfaat terutama apabila pengajar sedang berada diluar kota maka proses pembelajaran masih bisadilakukan. Penggunaan aplikasi online dinilai sangat relevan dengan kemajuan teknologi informasi mengingat banyaknya manfaat yang didapat dengan penerapannya secara luas pada taraf pengajaran di Perguruan Tinggi.

\subsection{Rumusan Masalah}

Berdasarkan latar belakang masalah tersebut, disusun perumusan masalah yaitu Bagaimana pemodelan website kelas online dengan mengunakan metode rekayasa web UML-based Web Engineering?.

\subsection{TINJAUAN PUSTAKA}

UML-based Web Engineering (UWE) merupakan salah satu metode rekayasa web, Karakter utamanya adalah pengunaan diagram Unified Modeling Language (UML) untuk semua model dan tahapan perancangannya.

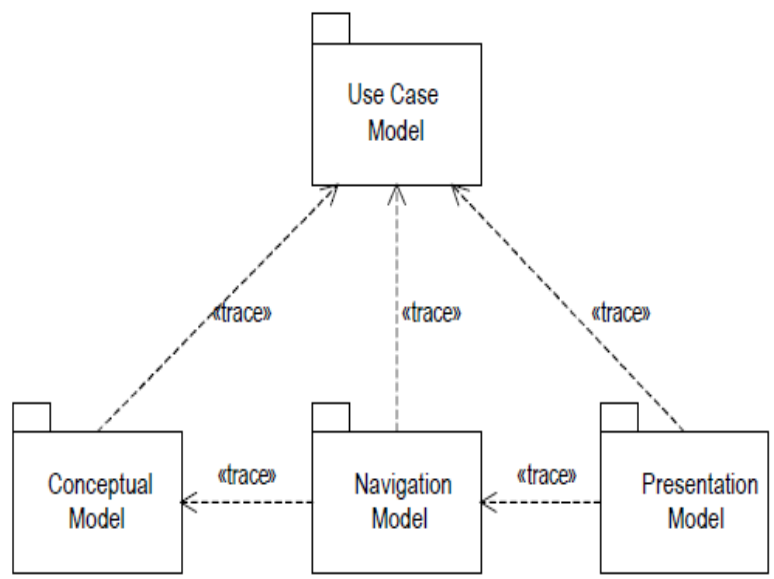

Gambar 1. Alur pemodelan mengunakan UWE

Tahapan pemodelan

1. Use Case Model (Requirements Model).

- Analisis penguna

- Use case diagramdigunakan untuk mengambarkan fungsi-fungsi didalam web.

- Definisi Aktor dan Definisi Use case.

- Activity diagramdigunakan untuk mengambarkan aliran kerja (Workflow) didalam web.

2. Conceptual Model (Content Model).

- Membuat konten web berdasarkan kegiatan aktor (use case).

- Class diagramuntuk mengambarkan struktur web, hubungan kegiatan aktor dan database.

- Sequence diagram \&State Chart diagram untuk mengambarkan interaksi dan sifat web.

3. Navigation Model

- Mendesain alur Navigasi didalam Web.

- Mempresentasikan Nodes dan Link didalam struktur web.

- Mencegah disorientasi didalam Web. 


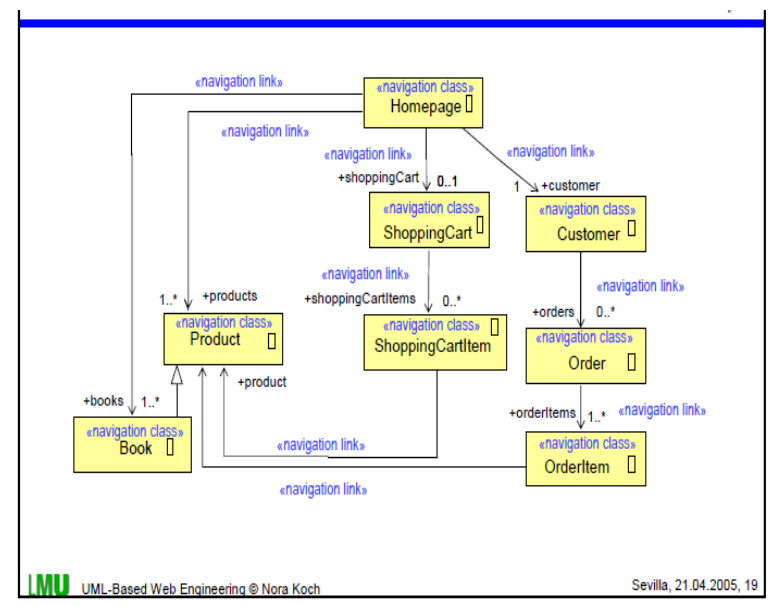

Gambar 2. Navigation Model

\section{Presentation Model}

- Representasi struktur web kedalam sebuah user interface.

- Desain Halaman Web

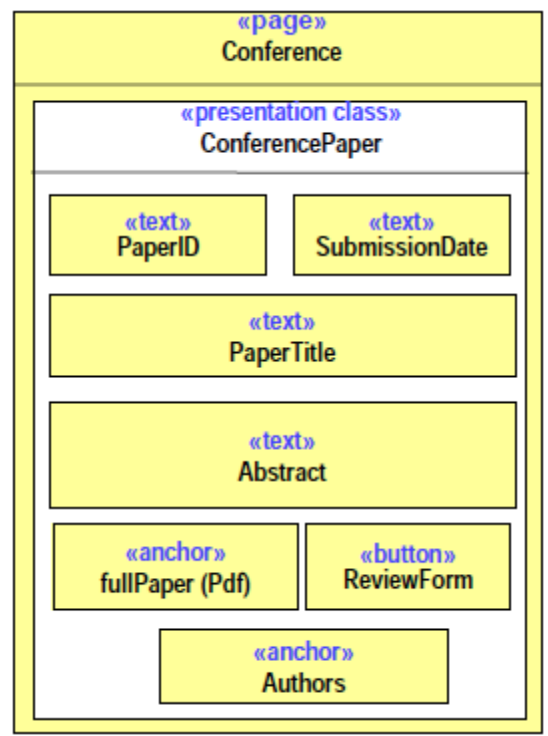

Gambar 3. Presentation Model

\section{Metode Penelitian}

Langkah-langkah penelitian, adalah sebagai berikut: 


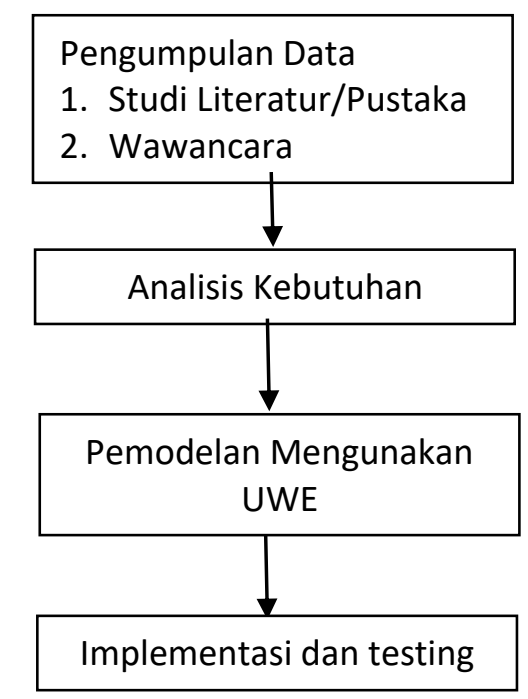

Gambar 4. Langkah-langkah penelitian

Langkah pengumpulan data dilakukan untuk memahami konsep dan kebutuhan untuk membangun konsep website kelas online. Langkah analisis kebutuhan langkah untuk menganalisis cara kerja sistem sesuai konsep dan kebutuhan jurusan teknik informatika Universitas Palangkaraya. Langkah pemodelan adalah langkah perancangan sistem website kelas online. Dan langkah implementasi dan testing adalah langkah pengkodean aplikasi dan pengujian aplikasi.

\section{Hasil Dan Pembahasan}

Pemodelan desain perangkat lunak mengunakan diagram UML. Diagram pertama mengunakan usecase untuk mendefinisikan penguna (aktor) dan aktivitasi penguna (case) menjadi class didalam aplikasi kelas online.

\section{Usecase Model}

1. Definis Aktor

2. Definisi Usecase

\begin{tabular}{ccl}
\hline No & \multicolumn{1}{c}{ Aktor } & \multicolumn{1}{c}{ Deskripsi } \\
\hline 1 & Admin & $\begin{array}{l}\text { Pengelola Web E-Learning } \\
\text { bertugas mengelola } \\
\text { peraturan web. }\end{array}$ \\
\hline 2 & Pengajar & $\begin{array}{l}\text { Pengajar yang memberikan } \\
\text { materi dan penilaian }\end{array}$ \\
\hline 3 & Siswa & $\begin{array}{l}\text { Siswa yang mengikuti } \\
\text { pelajaran pada web E- } \\
\text { learning }\end{array}$ \\
\hline 4 & Pengunjung & $\begin{array}{l}\text { Pengunjung web yang ingin } \\
\text { membuat akun pengajar } \\
\text { atau akun siswa. }\end{array}$ \\
\hline
\end{tabular}

\begin{tabular}{ccl}
\hline No & Aktor & \multicolumn{1}{c}{ Deskripsi } \\
\hline 1 & Login & $\begin{array}{l}\text { Fungsi untuk masuk kedalam } \\
\text { sistem dengan mengecek } \\
\text { username dan password pada } \\
\text { tabel akun dan tabel siswa. }\end{array}$ \\
\hline 2 & Kelola & $\begin{array}{l}\text { Fungsi untuk Pengajar untuk } \\
\text { memasukan bahan ajar yang } \\
\text { dapat dibuat langsung di web }\end{array}$ \\
\hline
\end{tabular}




\section{JURNAL TEKNOLOGI INFORMASI}

[E-ISSN 2656-0321]

[Vol 12. No. 1]

Jurnal Keilmuan dan Aplikasi Bidang Teknik Informatilka

[Januari 2018]

\begin{tabular}{|c|c|c|}
\hline & & $\begin{array}{l}\text { dan langsung dibaca oleh } \\
\text { siswa. Pengajar bisa } \\
\text { memasukan Text, image dan } \\
\text { Video pada materi. }\end{array}$ \\
\hline 3 & $\begin{array}{l}\text { Upload } \\
\text { PPT/PDF }\end{array}$ & $\begin{array}{l}\text { Fungsi untuk Pengajar } \\
\text { memasukan bahan ajar ke } \\
\text { web dengan format PPT atau } \\
\text { PDF sehingga siswa dapat } \\
\text { langsung membaca dan } \\
\text { mendonwload }\end{array}$ \\
\hline 4 & $\begin{array}{l}\text { Update } \\
\text { Password } \\
\text { Pengajar }\end{array}$ & $\begin{array}{l}\text { Fungsi untuk Pengajar } \\
\text { merubah Password untuk } \\
\text { login }\end{array}$ \\
\hline 5 & $\begin{array}{l}\text { Kelola } \\
\text { Pelajaran }\end{array}$ & $\begin{array}{l}\text { Fungsi untuk Pengajar } \\
\text { menambah pelajaran yang } \\
\text { diampu, juga didalam fungsi } \\
\text { ini terdapat fungsi tambahan } \\
\text { kelola Tugas dan Nilai } \\
\text { dimana pengajar dapat } \\
\text { melihat tugas yang masuk dan } \\
\text { memberikan penilaian. }\end{array}$ \\
\hline 6 & $\begin{array}{l}\text { Lihat Data } \\
\text { Siswa }\end{array}$ & $\begin{array}{l}\text { Fungsi untuk Pengajar } \\
\text { melihat data siswa yang dia } \\
\text { ajar per mata pelajaran. }\end{array}$ \\
\hline 7 & $\begin{array}{l}\text { Update } \\
\text { Password } \\
\text { Siswa }\end{array}$ & $\begin{array}{l}\text { Fungsi untuk Siswa merubah } \\
\text { Password untuk login }\end{array}$ \\
\hline 8 & $\begin{array}{l}\text { Pilih } \\
\text { Pelajaran }\end{array}$ & $\begin{array}{l}\text { Fungsi untuk Siswa memilih } \\
\text { pelajaran yang ingin diikuti }\end{array}$ \\
\hline 9 & Lihat Materi & $\begin{array}{l}\text { Fungsi untuk Siswa membaca } \\
\text { materi web atau file PPT/PDF } \\
\text { dan mendonwload materi } \\
\text { PPT/PDF }\end{array}$ \\
\hline 10 & $\begin{array}{l}\text { Upload } \\
\text { Tugas }\end{array}$ & $\begin{array}{l}\text { Fungsi untuk Siswa } \\
\text { mengupload tugas }\end{array}$ \\
\hline 11 & Daftar & $\begin{array}{l}\text { Fungsi untuk Pengunjung } \\
\text { mendaftar menjadi Pengajar } \\
\text { atau Siswa. }\end{array}$ \\
\hline 12 & $\begin{array}{l}\text { Lihat } \\
\text { Peraturan }\end{array}$ & $\begin{array}{l}\text { Fungsi untuk Pengunjung } \\
\text { melihat peraturan }\end{array}$ \\
\hline 13 & Kelola Akun & $\begin{array}{l}\text { Fungsi untuk Admin kelola } \\
\text { Seluruh Akun yang ada pada } \\
\text { database website }\end{array}$ \\
\hline 14 & $\begin{array}{l}\text { Kelola } \\
\text { Peraturan }\end{array}$ & $\begin{array}{l}\text { Fungsi untuk Admin untuk } \\
\text { kelola peraturan. }\end{array}$ \\
\hline
\end{tabular}

Setelah mendefiniskan aktivitas (case) maka dibuatlah diagram usecase berdasarkan definisi case yang telah dibuat. Diagram usecase mengambarkan kelompok class dan hubungannya dengan tabel pada database, sehingga memudahkan untuk membuat desain antarmuka penguna dan pengkodean pembuatan aplikasi. 


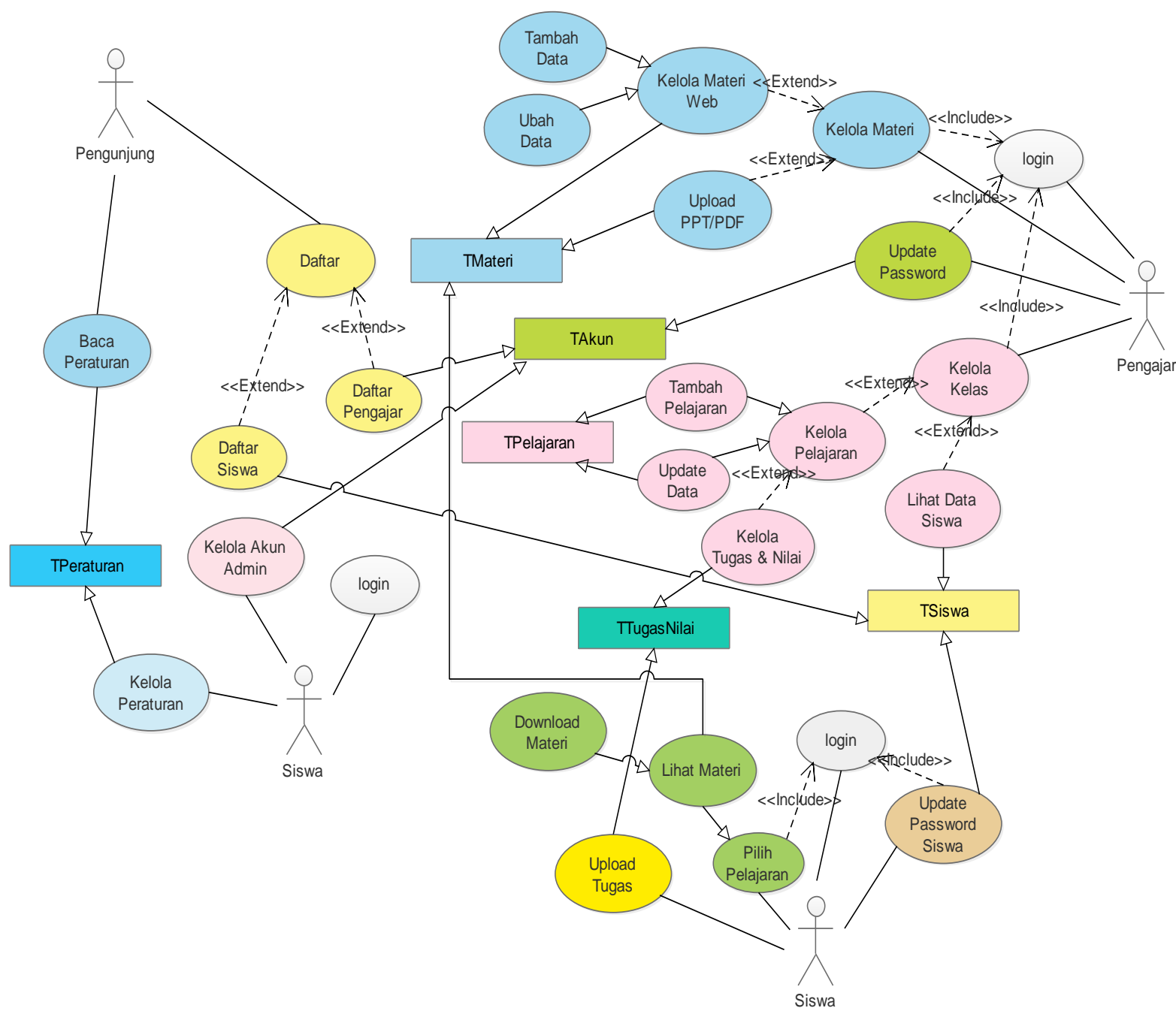

\section{Kesimpulan}

Desain dan perancangan dengan mengunakan UML-based Web Engineering dengan langkah sebagai berikut: pembuatan usecase model untuk mendefiniskan class-class untuk digunakan kembali pada proses berikutnya seperti concptual model, navigation model dan presentation model.

\section{Daftar Pustaka}

[1] Koch, Nora, Knapp, Alexander, Zhang, Gefei, and Baumeister, Hubert. 2005. UML-based WEB ENGINERRING [Online]. Situs :

https://pdfs.semanticscholar.org/cd42/5948157ed10a42279ff367caf0340cf2c26f.pdf [Di akses pada Juni 2017]

[2] Aji Supriyanto. 2007. Web dengan HTML dan XML. Yogyakarta. Penerbit : Graha Ilmu.

[3] Al-Bahra Bin Ladjamudin. 2013. Analisis dan Desain Sistem Informasi. Yogyakarta. Penerbit : Graha Ilmu 


\section{JURNAL TEKNOLOGI INFORMASI}

[E-ISSN 2656-0321]

[Vol 12. No. 1]

Jurnal Keilmutan dan Aplikasi Bidang Teknik Informatilka

[4] Arikunto, 2006. Prosedur Penelitian Suatu Pendekatan Praktik. Jakarta. Penerbit: Rineka Cipta.

[5] Bunafit Nugroho. .2008. Aplikasi Pemrograman Web Dinamis Dengan PHP dan MySQL. Yogyakarta. Penerbit : Gava Media.

[6] Henderi. 2006. UnifiedModellingLanguage. Tangerang. Penerbit: Raharja Enrichment Centre (REC).

[7] Ian, Sommerville. 2009. Software Engineering / Ian Sommerville - 9th ed. United State of America. Penerbit : PearsonEducation, Inc.

[8] Nugroho, Adi. 2011. Perancangan dan Implementasi Sistem Basis Data. Yogyakarta. Penerbit: ANDI

[9] Rossa A.S dan M. Shalahuddin. 2013. Rekayasa perangkat lunak : terstruktur dan Berorientasi Objek. Bandung. Penerbit : Informatika 